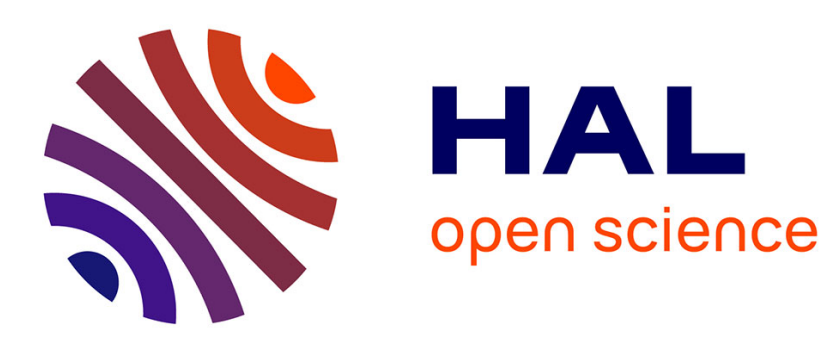

\title{
On-board Decision Making Platform for Structural Health Monitoring
}

Cécile Barthes, Marc Rebillat, Khalid Mosalam, Nazih Mechbal

\section{To cite this version:}

Cécile Barthes, Marc Rebillat, Khalid Mosalam, Nazih Mechbal. On-board Decision Making Platform for Structural Health Monitoring. International Workshop on Structural Health Monitoring, Sep 2017, Palo Alto, United States. pp.1-8. hal-01665331

\section{HAL Id: hal-01665331 https://hal.science/hal-01665331}

Submitted on 15 Dec 2017

HAL is a multi-disciplinary open access archive for the deposit and dissemination of scientific research documents, whether they are published or not. The documents may come from teaching and research institutions in France or abroad, or from public or private research centers.
L'archive ouverte pluridisciplinaire HAL, est destinée au dépôt et à la diffusion de documents scientifiques de niveau recherche, publiés ou non, émanant des établissements d'enseignement et de recherche français ou étrangers, des laboratoires publics ou privés. 


\title{
COVER SHEET
}

Title: On-board Decision Making Platform for Structural Health Monitoring

Authors :

\author{
Clément Barthès \\ Marc Rébillat \\ Khalid Mosalam \\ Nazih Mechbal
}

**IMPORTANT** All authors' information will appear on the program according to the submission stub on the online submission system (not to the manuscript). The title and author list provided in the manuscript will be for future referencing and citation.

PAPER DEADLINE: **May 15, 2017**

PAPER LENGTH: **8 PAGES MAXIMUM **

Please submit your paper in PDF format. We encourage you to read attached Guidelines prior to preparing your paper-this will ensure your paper is consistent with the format of the articles in the CD-ROM.

NOTE: Sample guidelines are shown with the correct margins.

Follow the style from these guidelines for your page format.

Electronic file submission: When making your final PDF for submission make sure the box at "Printed Optimized PDF" is checked. Also-in Distiller-make certain all fonts are embedded in the document before making the final PDF. 


\begin{abstract}
The ability to monitor the health of complex structures such as aeronautic or civil engineering structures in real time is becoming increasingly important. This process is referred to as structural health monitoring (SHM) and relies on onboard platforms comprising sensors, computational units, communication resources, and sometimes actuators. Many of such platforms have been developed within the last years but there is still a lack of structuration and knowledge exchange regarding the software and hardware architectures of such platforms. The aim of the present paper is to introduce an open hardware and open software platform dedicated to SHM within the fields of aeronautics and civil engineering. The platform presented here will be made available in an open hardware and open source framework to allow SHM researchers to run concurrent detection, localization, classification or quantification algorithms using simple interpreted languages such as Python.
\end{abstract}

\title{
THE STRUCTURAL HEALTH MONITORING (SHM) CHALLENGES
}

Structural health monitoring $[1,2,3]$ (SHM) consists of monitoring in real time the health state of structures, typically for civil engineering or aeronautic applications. At the core of modern SHM process targeted for industrial purposes lies a wireless platform able to send sensing signals to the actuators, to receive structural response from the sensors, and to process signals in order to make a decision regarding the eventuality of a damage. In the last decade, there has been several SHM platforms developed for this purpose $[4,5,6]$, using micro-controllers, and communicating via meshing radio networks such as ZigBee. Nonetheless, recent microprocessors allow running a small embedded Linux distribution on a chip, the size of a memory card, using less than half a Watt of power. Furthermore, numerous ways exist nowadays to connect a sensor to the Internet. Reliable radio technologies, e.g. WiFi and 4G-LTE, are already widely used, and long range low consumption radio standards have emerged and are now being deployed, e.g. LoRa and Sigfox. Therefore, we believe that the technology is now mature enough to create a shared platform that would solve most of the challenges that SHM researchers face today in circuit board design. Furthermore, this shared platform would allow to effectively alert decision-makers of any potential damage during an extreme event in a timely manner.

Hardware manufacturers have already adopted an open-source approach to push the technology forward and engage a larger community, despite the fierce competition opposing them. This approach is now considered the best to improve a system reliability, even in the field of computer security where releasing the source code was for long considered very risky. Similarly, the SHM research community will greatly improve the reliability of the developed algorithms with a shared modular platform.

\section{PLATFORM ARCHITECTURE}

In order to fulfill the basic requirements for both the aeronautical and civil engineering needs, the proposed platform may contain a GPS clock, high quality amplifiers and high-resolution digitizers, along with an embedded Linux distribution. The platform architecture is divided into three parts detailed in Figure 1. These are lumped as follows: (i) The advanced developer space, (ii) The simplified developer space, and (iii) The user 
space. The advanced developer space handles the communication with all the sensor and actuator conditioners, the radio modules, and the real-time processors. It is encapsulated in an abstraction layer, accessible from the simplified developer space. Any developer willing to add a core feature to the platform has to program in this space. However, the simplified developer space is where most researchers are expected to be coding. It allows to read sensor data, but also to control basic sensor configuration, e.g. changing sampling rate and zeroing strain gauges and load cells. This space also contains a web server, using Node.js (an open-source, cross-platform JavaScript interpreter often used as a web server). These two developer spaces are accessible remotely using Secure SHell (SSH) connection. This type of connection grants access to the entire Linux environment, allowing developers to securely update their codes, even in nodes that are already deployed. On the other hand, the user space is accessed from a web client, e.g. Chrome or Firefox. For privacy considerations, e.g. the confidential critical infrastructure data, this space can be password protected, and several access levels can be defined. The privileges given to users are defined in the simplified developer space. For instance a developer may grant users access to view live data stream scopes, or to download data archives stored on the node.

The benefits of such architecture are two folds. First, it will allow users to rapidly deploy any SHM algorithm on a remote platform without having any low-level programming skills. Second, it will allow users to run benchmark tests between various SHM algorithms and thus strengthen links and exchanges within the SHM community.

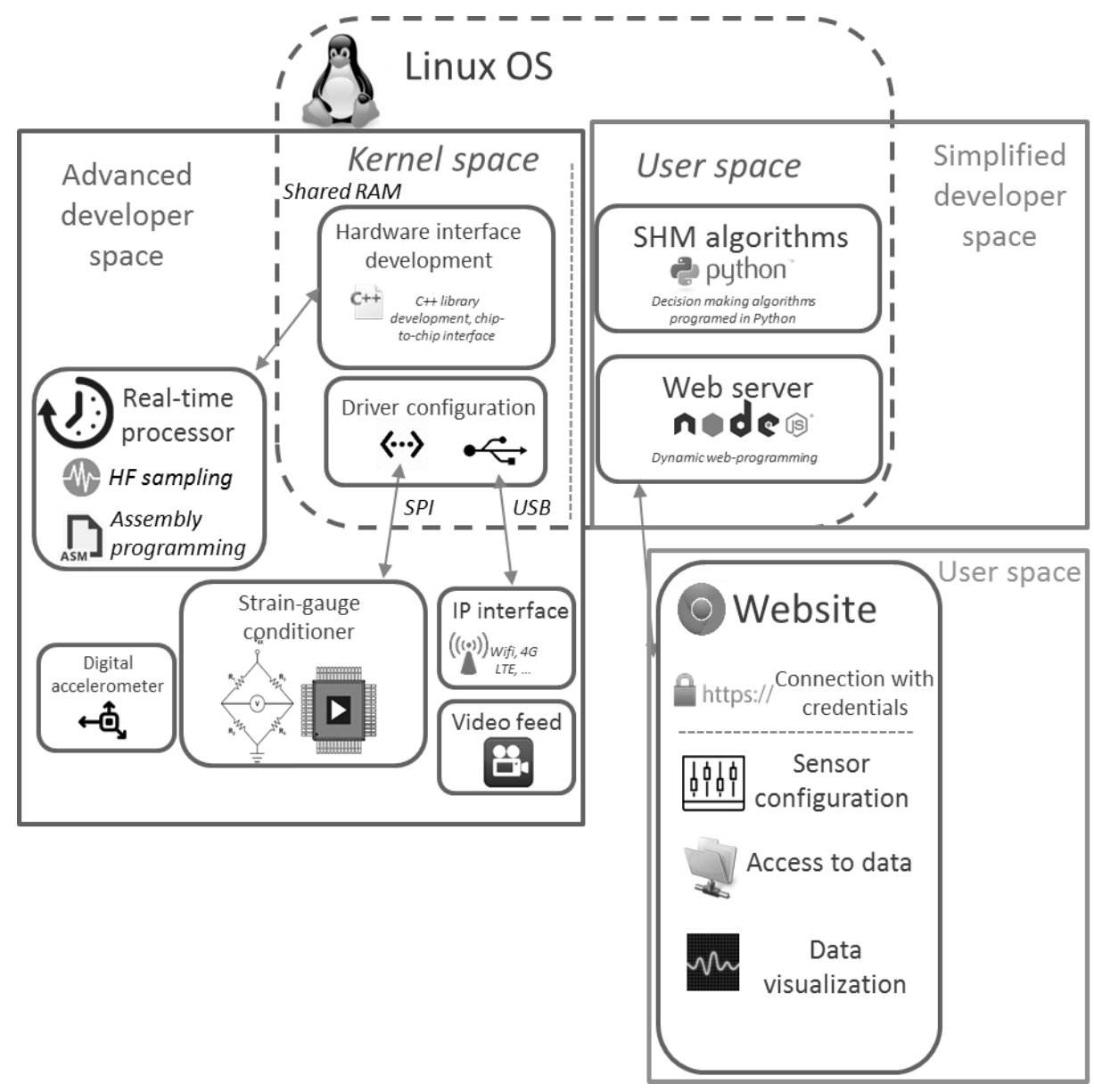


The platform architecture presented here is intended to be flexible enough to be used in most SHM applications. Hence, a single circuit board design cannot be used for all applications. In fact, it is expected that dozens of circuit board designs will coexist. However, all the platforms will benefit from the hardware integration libraries, the signal processing algorithms and the web interface modules. Every time a new feature is developed, all the platforms which contain the required hardware will benefit from the upgrade. For instance, a Python module to receive video stream from a Gopro camera over a USB port and WiFi is being developed. As soon as this feature will become available, all the platforms with a WiFi connection or a USB host will be able to interact with the camera, receive a video stream and process it. Moreover, as the community grows and publishes new algorithms, developers will be able to upload new SHM algorithms onto already deployed nodes.

\section{USE CASES}

\section{Infrastructures subjected to extreme events}

After a severe event such as an earthquake, it is essential to assess induced damage of all major infrastructures [3]. Indeed, if a lifeline infrastructure, e.g. a highway bridge [7, $8,9]$ is unable to operate, or if a public building $[10,11]$ constitutes a major lifethreatening risk, the first responders must be informed in order to take appropriate measures. Hence, as communities attempt to improve their resiliency, SHM should become an essential part of their plans. The headquarters of the Pacific Earthquake Engineering Research (PEER) Center at the University of California, Berkeley (UCB) intends to bridge the gap between the SHM community and the large infrastructures key decision-makers. First, the embedded web server allows to quickly develop tailored interfaces for bridge and building inspectors. Furthermore, the open framework allows to run the fleet of sensors in simulation mode. Hence, it is possible to organize workshops with inspectors and decision-makers, simulate various risk (hazard, exposure and vulnerability) scenarios and train the attendees to interpret the data adequately. 


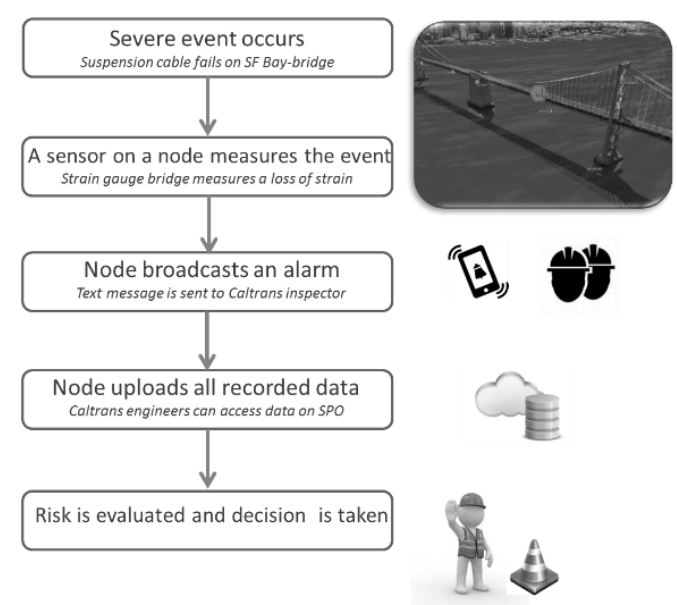

(a) Response initiated by a sensor node

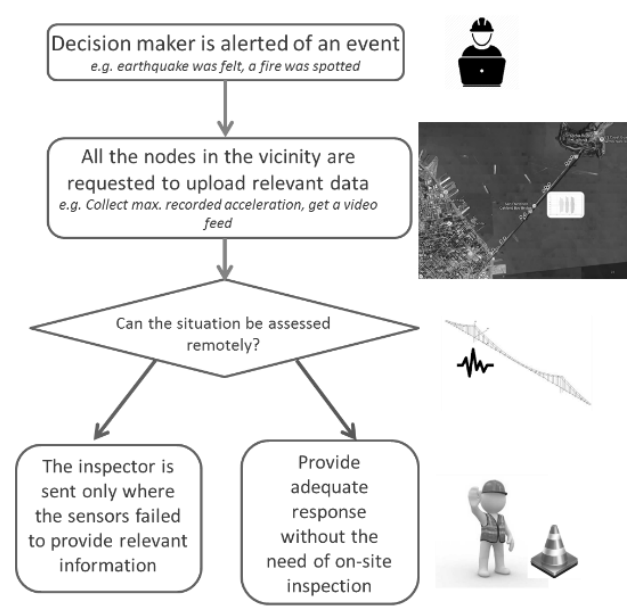

(b) Response initiated by an inspector

Figure 2. Fleet of sensors deployed on a large infrastructure to help with the decision making process

Figure 2 represents two possible scenarios for SHM of a large bridge system subjected to an earthquake event. In case (a), an inspector receives an alarm from a sensor node and uses the data received to make an adequate decision. In case (b), an inspector is alerted of an event and uses the fleet of sensor nodes to assess the situation.

\section{SHM of aircraft stiffened composite components}

Stiffened composite structures are very appealing in aeronautic applications due to their unique high stiffness to mass ratio. However, they are also prone to various and complex damage scenarios (stiffener debonding, impact damage, etc.) and to complex wave propagation phenomena due to the presence of the stiffener. Consequently, autonomous monitoring of such structures is still an open research topic [12]. To detect damage, stiffened composite structures are equipped with piezoelectric (PZT) elements that act as both sensors and actuators. A database at the unknown (and possibly damaged) state is then compared to a healthy reference database. Several damage indices (DIs) formulated for the purpose of detection are extracted from this comparison. A methodology proposed for the detection of damage induced on the stiffened composite structure that can be embedded on the developed platform is summarized in Figure 3. 


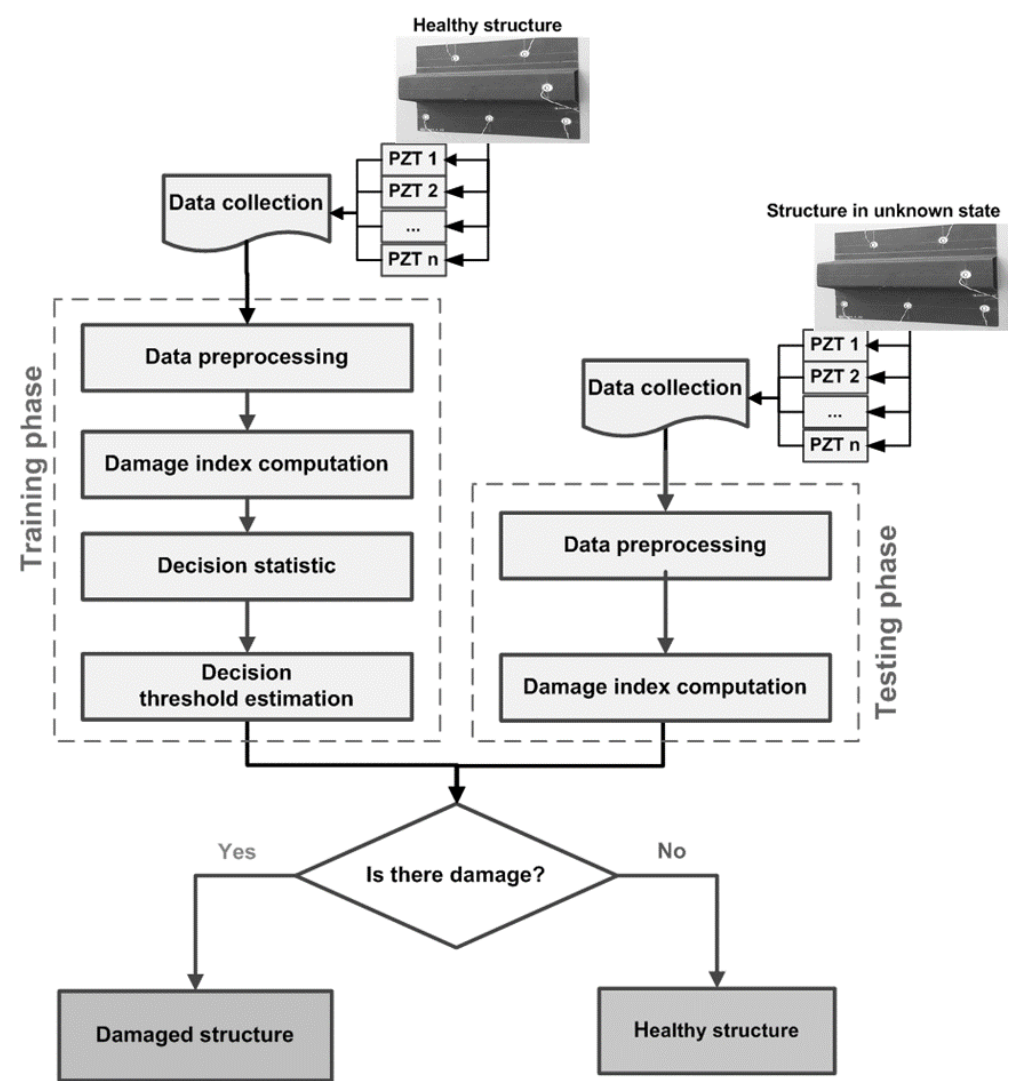

Figure 3: Damage detection methodology for the inspection of stiffened composite structures.

SHM is achieved in the case of stiffened composite structures by means of Lamb waves $[9,10]$. This method is based on the principle that Lamb waves can propagate in the body of the structure and will necessarily interact with damage. Information is then extracted from the waves diffracted by the damage for detection purposes. In each phase of the experimental procedure, one PZT is selected as the actuator and the others act as sensors. All the PZTs act sequentially as actuators. The resulting signals are then simultaneously recorded by the other piezoelectric elements. For all configurations, several repetitions are performed to have sufficient data for a statistical approach. On the basis of these available signals, damage indices can be computed to facilitate decision-making regarding the health state of the stiffened composite structure.

\section{PLATFORMS UNDER DEVELOPMENT}

\section{Viscous damper monitoring}

The PEER Center laboratory at UCB has developed a preliminary SHM module for bridge monitoring, Figure 4(a) which is intended for monitoring the 96 dampers of the West span of the San Francisco-Oakland Bay bridge. The module contains a custom Linux distribution specifically designed to run on an embedded platform. The current prototype runs on an Intel Atom dual-core processor, but it can be easily ported to a Linux-compatible processor from another manufacturer where the interface is entirely web-based. Cutting-edge HTML5 features offer very dynamic web display. A simple web page can display real-time plots and offer buttons to interact with the device, refer to Figure 4(b). 
(a)

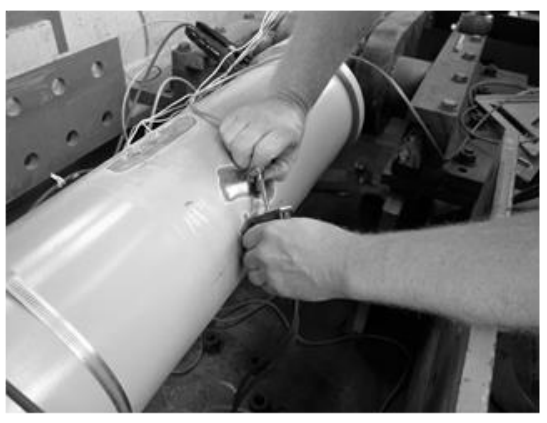

(b)

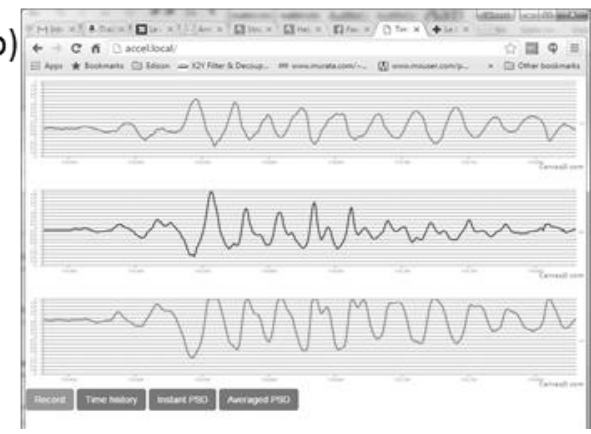

Figure 4. PEER SHM prototype to monitor the Bay Bridge dampers, (a) Strain-Gauge being welded (b) Web interface.

\section{Multi-channels high-speed data acquisition system}

PEER at UCB and Ecole Nationale Supérieure d'Arts et Métiers (ENSAM), Paris are developing a platform with 8 high-speed analog-to-digital converters (ADCs), refer to Figure 5. All channels sample simultaneously at $1 \mathrm{MHz}$ with a 16 bits resolution. This platform is aimed to measure piezoelectric transducers and perform damage assessment using Lamb waves propagation.

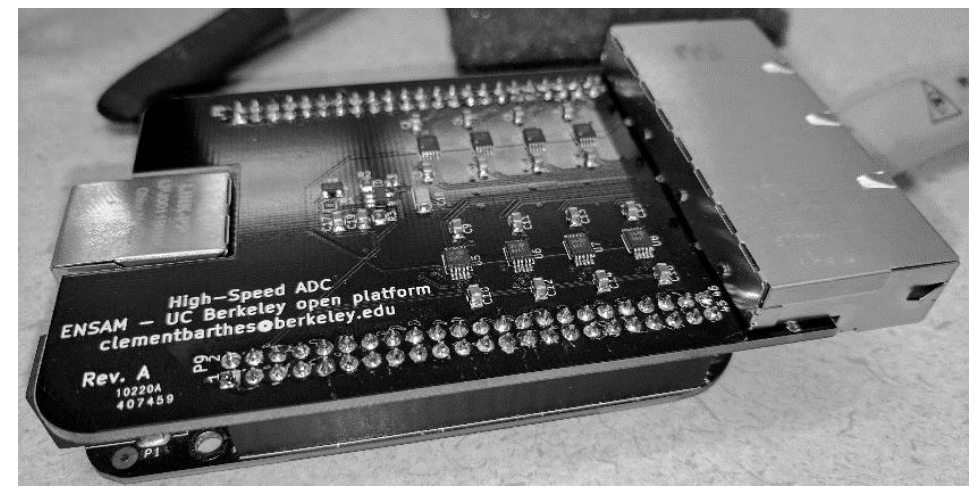

Figure 5: The SHM board designed in collaboration between PEER laboratory and ENSAM Paris

\section{References}

[1] D. Balageas, C.-P. Fritzen and A. Guemes, Structural health monitoring, vol. 493, Wiley Online Library, 2006.

[2] C. R. Farrar and K. Worden, "An introduction to structural health monitoring," Philosophical Transactions of the Royal Society of London A: Mathematical, Physical and Engineering Sciences, vol. 365, no. 1851, pp. 303-315, 2007.

[3] A. Rytter, "Vibrational based inspection of civil engineering structures," 1993.

[4] J. Cao and X. Liu, "Wireless sensor networks for structural health monitoring," SpringerBriefs in electrical and computer engineering (, 2016.

[5] S. Kim, S. Pakzad, D. Culler, J. Demmel, G. Fenves, S. Glaser and M. Turon, "Health monitoring of civil infrastructures using wireless sensor networks," in Proceedings of the 6th international conference on Information processing in sensor networks, 2007.

[6] J. P. Lynch and K. J. Loh, "A summary review of wireless sensors and sensor networks for structural health monitoring," Shock and Vibration Digest, vol. 38, pp. 91-130, 2006.

[7] Y. Arici and K. Mosalam, "Modal Identification of Bridge Systems Using State-Space Methods," Journal of Structural Control and Health Monitoring, vol. 34, no. 10, pp. 1323-12341, 2005. 
[8] K. Mosalam and Y. Arici, "System Identification of Instrumented Bridge Systems," Earthquake Engineering and Structural Dynamics, vol. 32, pp. 999-1020, 2003.

[9] Y. Arici and K. Mosalam, "Health Monitoring of a Bridge System Using Strong Motion Data," Smart Structures and Systems, vol. 5, no. 4, pp. 427-442, 2009.

[10] Y. Yang, H. Liu, K. Mosalam and X. Huang, "An Improved Direct Stiffness Calculation Method for Damage Detection of Beam Structures," Structural Control and Health Monitoring, vol. 20, no. 5, pp. 835-851, 2013.

[11] Y. Yang, K. Mosalam, H. Liu and X. Wang, "Damage Detection Using Improved Direct Stiffness Calculations - A Case Study," International Journal of Structural Stability and Dynamics, vol. 16, no. $1640002,2015$.

[12] C. Fendzi, N. Mechbal, M. Rebillat and M. Guskov, "A General Bayesian Framework for Ellipsebased and Hyperbola-based Damage Localisation in Anisotropic Composite Plates," Journal of Intelligent Material Systems and Structures, vol. 27, no. 3, pp. 350-374, $2016 \mathrm{a}$.

[13] Z. Su and L. Ye, Identification of damage using Lamb waves: from fundamentals to applications, vol. 48, Springer Science \& Business Media, 2009.

[14] H. Sohn, D. W. Allen, K. Worden and C. R. Farrar, "Structural damage classification using extreme value statistics," 2005.

[15] L. De Haan and H. Rootzén, "On the estimation of high quantiles," Journal of Statistical Planning and Inference, vol. 35, no. 1, pp. 1-13, 1993.

[16] E. Parzen, "On estimation of a probability density function and mode," The Annals of Mathematical Statistics, vol. 33, no. 3, pp. 1065-1076, 1962.

[17] B. W. Silverman, Density estimation for statistics and data analysis, vol. 26, CRC press, 1986. 


\section{DEStech Publications, Inc.}

\section{CONTRIBUTING AUTHOR COPYRIGHT RELEASE FORM}

As author of the chapter/contribution titled On-board Decision Making Platform for Structural Health Monitoring, to appear in the Proceedings of Structural Health Monitoring 2017, I hereby agree to the following:

1. To grant to DEStech Publications, Inc., 439 North Duke Street, Lancaster, PA, 17602, copyright of the above named chapter/contribution (for U.S.

Government employees to the extent transferable), in print, electronic, and online formats. However, the undersigned reserve the following:

a. All proprietary rights other than copyright, such as patent rights.

b. The right to use all or part of this article in future works.

DEStech Publications thereby retains full and exclusive right to publish, market, and sell this material in any and all editions, in the English language or otherwise.

1 I warrant to DEStech Publications, Inc., that I am the (an) author of the above-named chapter/contribution and that I am the (a) copyright holder of the above-named chapter/contribution granted to DEStech Publications, Inc.

2 I warrant that, where necessary and required, I have obtained written permission for the use of any and all copyrighted materials used in the abovenamed chapter/contribution. I understand that I am responsible for all costs of gaining written permission for use of copyrighted materials.

3 I agree to assume full liability to DEStech Publications, Inc. and its licensee, and to hold DEStech Publications, Inc. harmless for any claim or suit filed against DEStech Publications, Inc. for violation of copyrighted material used in the abovenamed contribution.

Please sign and date this form and retain a copy for your records. Please include original form with your chapter/paper.

Thank you for your cooperation.

Please print name: Clement Barthes

Signed:

Dated: $05 / 31 / 2017$

439 NORTH DUKE STREET - LANCASTER, PENNSYLVANIA 17602-4967, U.S.A. Toll Free: (866) 401-4337 • Tel: (717) 290-1660 • Fax: (717) 509-6100 E-mail: info@destechpub.com • Internet address: www.destechpub.com 